\title{
Counter Terrorism: Risk Perception and Communication in Naturalistic Environments
}

\author{
Claire McAndrew \& Teal Triggs \\ London College of Communication, University of the Arts London \\ c.mcandrew@1cc.arts.ac.uk; t.triggs@1cc.arts.ac.uk
}

\begin{abstract}
Motivation - This research examines risk perception and the process of interactive counter terror communication in order to reduce the fear associated with security technologies in public spaces. Research approach - Using focus groups, data collection will adopt a two-stage design assessing (i) public perceptions of current counter terror communications and (ii) the effectiveness of interactive counter terror communication tools. Research limitations / Implications - Despite limitations associated with the generalisability of findings to other UK cities and countries, it is hoped that this research will produce evidence-based advice on how best to communicate with the UK public. Originality / Value This research demonstrates the utility of researchers engaging in risk research collaborating with communication designers to develop state-of-the art communication tools. Take away message - When situated in a naturalistic environment, interactive communication tools can be used as an interface to manage the public's risk perceptions in relation to counter terror technologies.
\end{abstract}

Keywords

Counter terrorism, risk perception, communication, interactive technology.

\section{INTRODUCTION}

Our work is motivated by recent studies conducted within the behavioural decision sciences, which have applied knowledge of risk perception and communication to the domain of terrorism. See for example, Maule, Cameron, Todd \& Stanley's (2008) field experiments testing predictions about methods of increasing the effectiveness of terror risk communications and Fischoff's extensive work (2002; 2004; 2005; Fischoff, Gonzalez, Lerner \& Small, 2005) on assessing and communicating the risks of terrorism to the public. Whilst this work has focused upon the likelihood of terrorist events occurring, it has not sought to communicate the converse i.e. how this risk is managed by Government agencies through the implementation of counter terror technologies. The proliferation of security technologies in the UK transport network post $9 / 11$ and $7 / 7$, has presented a growing need for Government agencies to manage public perceptions in order to foster acceptance of these new technologies. For instance, research examining attitudes in relation to the experience of passenger screening in the UK, has suggested the acceptability of counter terror technologies to be inextricably tied to the public's understanding of and 'physical connection' with security measure procedures in operational environments (Department for Transport, 2006). This finding, coupled with research suggesting that the public worry about unknown, invisible risks (Slovic, 1987) and that these emotional responses to risk can both confound and support cognition (Small, Lerner \& Fischhoff, 2006), has created the impetus for this research. Our work seeks to explore existing risk perceptions in relation to counter terror technologies and examine the effectiveness of public engagement with an interactive communication tool (embedded with elements of counter terror technology and positioned in situ) in reducing the fear associated with these security measures.

\section{METHODS}

In order to assess (i) public perceptions of current counter terror communications and (ii) the effectiveness of interactive counter terror communication tools, data collection will take place in two stages. Five focus groups comprising eight participants will take place during stage one $(n=40)$. This will provide an understanding of participants' existing perceptions of counter terror communications and security technologies. This information will inform the development of an interactive communication tool (that embodies an element of security technology) in collaboration with an architect / interaction designer and experts in the field of sensors technology. During stage two, eight groups formed of eight participants $(n=64)$ will engage with the interactive communication tool and then complete the focus group as per stage one. A 'control' set of focus groups will also occur during stage two (three groups of eight participants (n=24)) who will not interact with the interactive communication tool. Our sample will be drawn from London residents who either: (i) commute on a daily basis or (ii) use the transport network less regularly using different stations / routes.

\section{FINDINGS}

Data collection is currently underway and due for completion in early 2009. The findings will be qualitatively analysed and data from stages one and two triangulated (Denzin, 1978). It is envisaged that this approach will help establish 


\author{
McAndrew $\bullet$ Triggs \\ Counter Terrorism: Risk Perception and Communication
}

whether reduced fear of counter terror measures is due to the effectiveness of the interactive communication tool or due to factors that have emerged in the external environment in the intervening period.

\title{
CONCLUSIONS
}

This research makes a number of contributions. First, it is envisaged that the findings will demonstrate the utility of researchers engaging in risk research (from both the NDM community and the broader decision sciences) collaborating with communication designers in order to develop state-of-the-art communication tools. Second, it is hoped that our user-focus will demonstrate that although useful, experts' understanding of risk is not sufficient and does not always extend to the public realm (Jenkin, 2006; Rogers, Amlôt, Rubin, Wessely \& Krieger, 2007). Third, we envisage this research will contribute towards the creation of a two-way dialogue between the public and academia / government agencies (Stout, 2004a,b). Finally, as Stout (2004a) and Brandon (2002) note, the solution to the challenges posed by terrorism will not simply be found in technological fixes, but will require a more complex understanding of the psychology of decision-making, notions of surveillance, fear, and understanding of human-machine interactions. As such, we see our work contributing by providing insights into the way in which interactive technologies can be used a tool to support and manage uncertainty and sense-making processes when placed in naturalistic environments (McAndrew, 2008).

\section{ACKNOWLEDGMENTS}

We wish to thank the EPSRC, ESRC, AHRC and the Centre for the Protection of National Infrastructure for funding the project 'Safer Spaces: Communication Design for Counter Terror' (EP/F008503/1) upon which this work is based. We would also like to express our gratitude to our Government partners and project team for their valued contributions.

\section{REFERENCES}

Brandon, S.E. (2002). Combating terrorism: Some responses from the behavioral sciences, Science Directorate, American Psychological Association. http://www.apa.prg/ppo/issues/terrorhome.html (Accessed: 30/09/08).

Denzin, N. (1978) Sociological methods: A sourcebook, McGraw Hill, New York.

Department for Transport (2006) Summary of the 'LUNR' passenger screening trials. http://www.dft.gov.uk/pgr/ security/land/lunr (Accessed: 30/09/08).

Fischoff, B. (2002) Assessing and communicating the risks of terrorism. In A.H. Teich, S.D. Nelson, \& S.J. (Eds.), Science and technology in a vulnerable world (pp. 51-64). AAAS, Washington.

Fischhoff, B. (2004) Realistic risk disclosure in newly normal times. In P. Shane, J. Podesta \& R.C. Leone (Eds.), Security, technology and privacy: A little knowledge (pp. 39-56). The Century Foundation, New York.

Fischhoff, B. (2005) Risk perception and communication. In D. Kamien (Ed.), McGraw-Hill handbook of terrorism and counter-terrorism (pp. 463-492). McGraw-Hill, New York.

Fischhoff, B., Gonzalez, R.M., Lerner, J.S. \& Small, D.A. (2005) Evolving judgments of terror risks: Foresight, hindsight, and emotion, Journal of Experimental Psychology: Applied, 11, 124-139.

Jenkin, C.M. (2006) Risk perception and terrorism: Applying the psychometric paradigm, Homeland Security Affairs, 2 , $2,1-14$.

Maule, A.J., Cameron, L., Todd, Z. \& Stanley, N. (2008) Perception and communication of the risk of terrorism. New Security Challenges Programme, http://www.esrcsocietytoday.ac.uk/esrcinfocentre/viewawardpage.aspx?Award number=RES-228-25-0053 (Accessed 30/09/08).

McAndrew, C. (2008) Cross-fertilising methods in naturalistic decision making and managerial cognition, Unpublished $P h D$ Thesis, University of Surrey, UK.

Rogers, M.B., Amlôt, R., Rubin, G.J., Wessely, S. \& Krieger, K. (2007) Mediating the social and psychological impacts of terrorist attacks: The role of risk perception and risk communication, International Review of Psychiatry, 19, 3, $279-288$.

Slovic, P. (1987) Perception of risk, Science, 236, 280-285.

Small, D.A., Lerner, J.S. \& Fischhoff, B. (2006) Emotion priming and attributions for terrorism: Americans' reactions in a national field experiment, Political Psychology, 27, 289-298.

Stout, C.E. (2004a). The psychology of countering terrorism with technology, IEEE Engineering in Medicine and Biology Magazine, 23, 1, 142-148.

Stout, C.E. (2004b). Using psychology to counter terrorism at the personal and community level. In C.E. Stout (Ed.), Psychology of terrorism: Coping with the continuing threat (pp.1-31). Greenwood, Westport. 